\title{
INFECÇÃO DO CÃO PELA LEISHMANIA
}

PELO

DR. ALEXANDRINO M. PEDROSO

Director do Laboratorio Anatomo=Pathologico da Santa Casa de Säo Paulo e Professor de Microbiologila da Faculdade de Medicina e Cirurgila

(Continuação e fim)

Parece, talvez, que o resultado desta experiencia anima seus ideaes; para nós, entretanto, a razão deve ser outra; não a differença biologica do agente infectante, mas a idade do animal infectado.

Esta supposição é tanto mais plausivel, si nos lembrarmos que o animal com o qual Laveran obteve a evolução completa da doença era uma cadella de seis meses, e que o "virus" empregado por elle foi obtido no Oriente.

Fóra estas inoculações, com culturas de Leishmania, obtidas do homem, fizemos appanecer as seguintes inoculações, com culturas humanas:

Tres cães de menos de um mez receberam a infecção intradermica de cultura humana. Em dois destes cães a doença nunca se desenvolveu, emquanto que no terceiro, desde o segundo mez, um nodulo se desenvolvia no local da infecção, que se transformou, mais tarde, em grande ulceração que se extendeu até a parte interna das narinas.

Nieste animal a lesão, por sua extensão e seu desenvolvimento, era muito semelhante áquellas que se bbservam na Leishmaniose expontanea do cão; mas depois de um anno e apezar das alternativas, ora melhores, ora peiores, a doença termina pela cura completa, ficando, entretanto, o animal com uma grande e disforme cicatriz. 

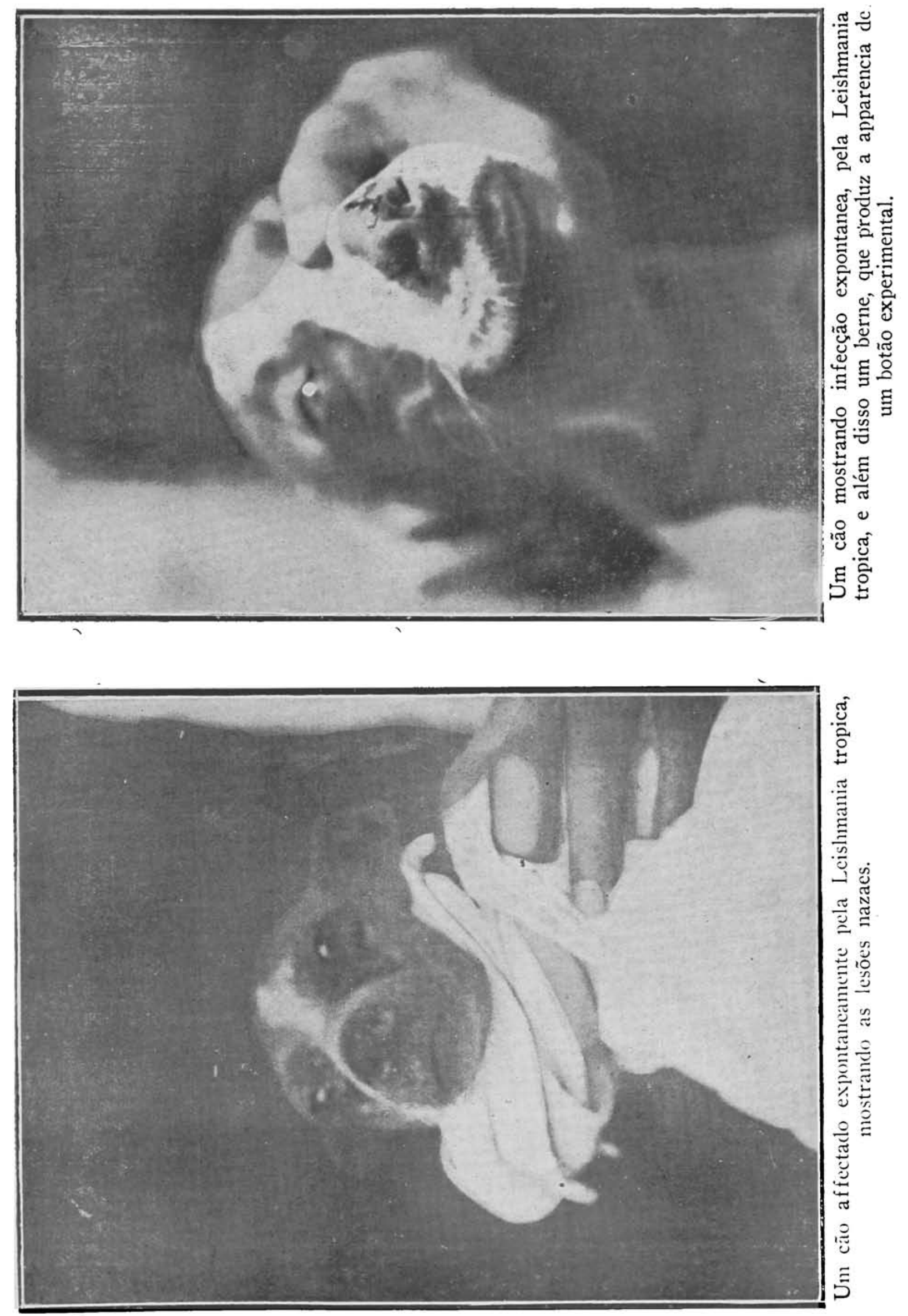



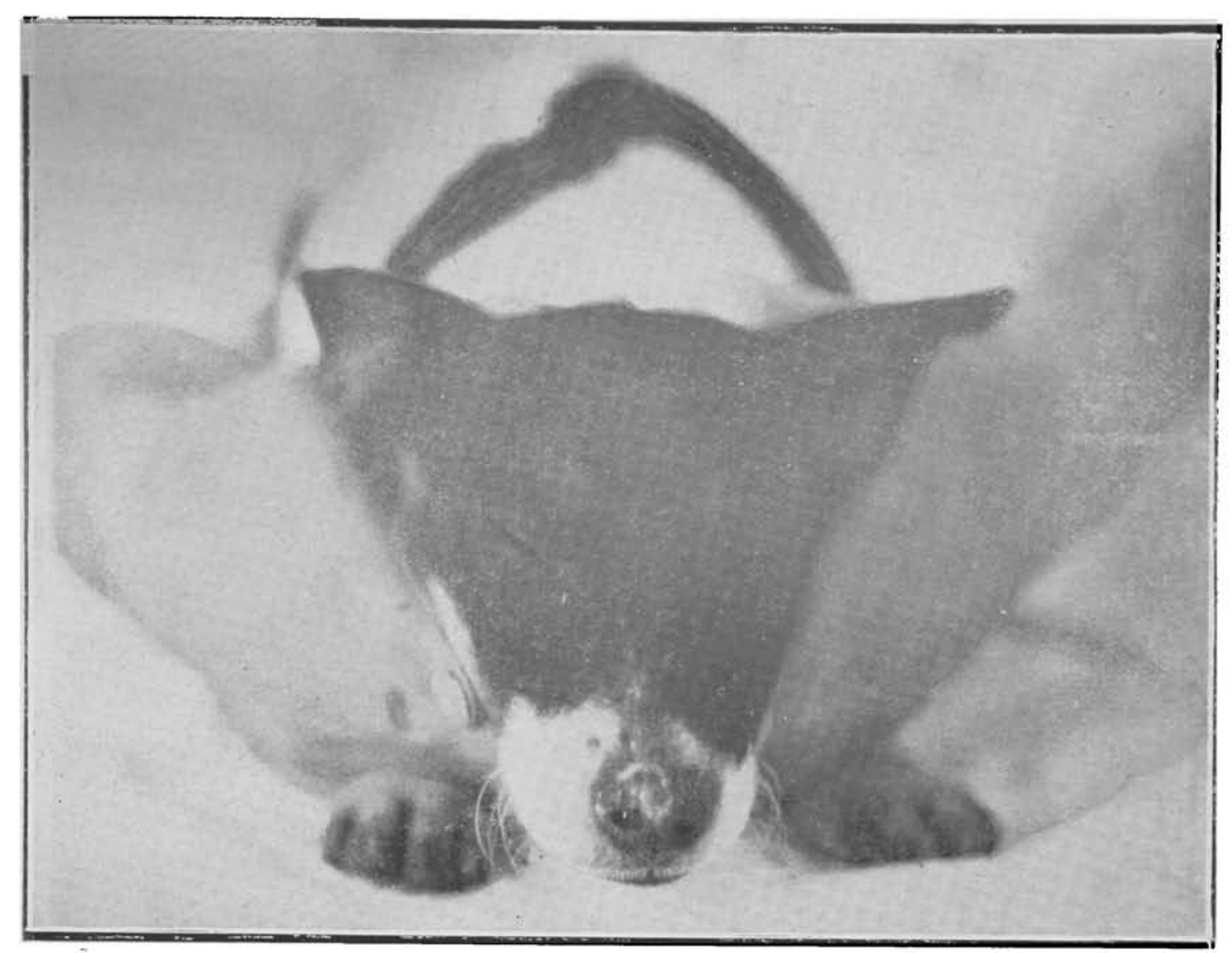

Este cão contava 3 mezes de idade, quando foi inoculado experimentalmente com Leishmania tropica da segunda repicagem, em 26-5-2̌2. O botão appareceu em 15-7-22, e foi seccionado para exame histologico. A ulceração conta 3 mezes.

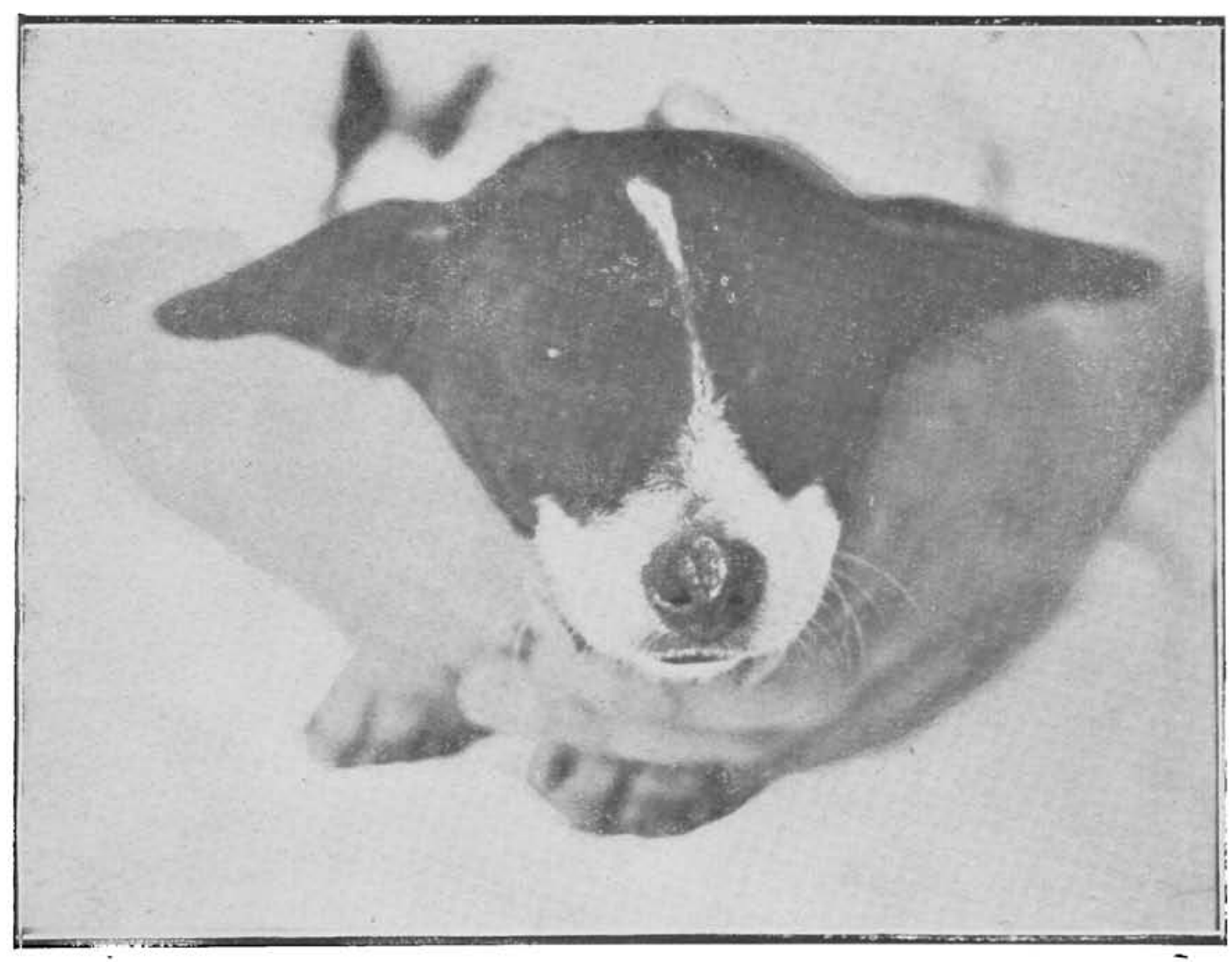

Cão da mesma idade inoculado nas mesmas circumstancias do anterior. O botão foi observado em 6-8-22. A ulceração conta 2 mezes e dias. 

Esta experiencia vem demonstrar que não se consegue sempre infeccionar o animal e que a gravidade e a extensão da doença variam de accôrdo com factores ainda não determinados.

A cadella, que apresentava a doença expontaneamente, teve tres cãesinhos quando ainda apresentava uma pequena ulceração nas narinas, que estavam largamente disformes.

Dois destes animaes foram inoculados com cultura humana de Leishmania.

Nenhum delles apresentou uma lesão qualquer no ponto da inoculação.

$\mathrm{Na}$ segunda cria, de dois cachorrinhos, no unico cão inoculado a molestia se desenvolveu.

A Leishmania tegumentar produz uma immunidade accentuada no individuo que a adquire e que della se tenha sahido bem; mas pelo resultado desta experiencia vê-se que tal immunidade não se prolonga aos filhos.

Do caso de Leishmaniose com manifestações mucosas, temos retirado o material duma ulcera do braço e depois de ter triturado bem o tecido, inoculamos, em identicas condições, no couro do nariz de dois outros animaes.

Um destes animaes adquiriu a molestia, que se ulcerou quasi um mez depois da inoculação, levando quasi 6 mezes para a cicatrisação completa.

Este animal foi mordido por um cão hydrophobo e foi por esse motivo sacrificado.

Com esta experiencia, vemos que, mesmo quando o "virus" é retirado dum máo caso, com lesão múcosa, a doença se reproduz no cão, com os mesmos caracteres observados na inoculação de cultura.

Um destes cães com leishmaniose expnotanea, o qual já citamos, apresentava lesões nasaes que permittiam a cultura parcial do parasito.

Com esta cultura obtida inoculamos dois cães de dois mezes de idade.

Dois mezes depois da data da inoculação percebemos a apparição de um nodulo nos dois animaes. A doença teve sua evolução natural, estando cicatrisada em menos de um anno.

O aspecto hysto-pathologico da lesão não ulcerada é duma intensa proliferação endothelial.

Chegamos as seguintes conclusões:

Esta cadella viveu durante alguns annos, no canil da "Santa Casa", tendo desapparecido mais tarde. 
1. - A Leishmaniose humana póde ser reproduzida experimentalmente no cão, com a mesma evolução e o mesmo aspecto microscopico.

$2 .^{\circ}$ - A fórma mucosa da molsetia não é reproduzida no animal com o mesmo aspecto clinico.

3. ${ }^{\circ}$ - Quanto mais jovem fôr o animal, tanto mais grave e maior é a lesão produzida.

4. ${ }^{\circ}$ - A immunidade não se prolonga aos filhos.

"MANTEIGA PHOSPHATADA SIMÕES"

PASTEURIZADA - PURA SABOROSA - PARA CREANÇAS E ADULTOS NOS ALIMENTOS E NA MESA. A' VONTADE

$$
\text { ALIMENTA - } \overline{\text { NUTRE }} \text { - TONIFICA }
$$

Confeitarias, Leiterias, Pharmacias, Drogarias, e Casas de comestiveis de ordem, ARMAZEM CoLOMBO, Praça José Alencar, deposito, rua dos Andradas, 43, 45 e 47, Rio e em S. Paulo, Almeida Loyolla \& C., rua 11 de Agosto n. 12; Confeitaria Fazoli, rua Direita n. 5.

A A Manteiga Phosphatada Simões; está approvada pelo Departamento Nacional de Saúde Publica do Río de Janeiro sob n. 935 em 24-8-822, e registrada na Junta Commercial sob n. ${ }^{\circ}$ 18.283. 